\title{
INTERFERÊNCIA de CAPIM-ARROZ (Echinochloa spp.) NA CUlTURA do ARROZ IRRIGAdo (Oryza sativa) EM FUNÇÃo DA ÉPOCA DE IRRIGAÇÃO ${ }^{1}$
}

\author{
Barnyardgrass (Echinochloa spp.) Interference in Flooded Rice (Oryza sativa) in Function of \\ Irrigation Timing
}

\author{
AGOSTINETTO, D. ${ }^{2}$, GALON, L. ${ }^{3}$, MORAES, P.V.D. ${ }^{3}$, TIRONI, S.P. ${ }^{4}$, DAL MAGRO, T. ${ }^{3}$ e \\ VIGNOLO, G.K. ${ }^{4}$
}

\begin{abstract}
RESUMO - A adoção de novos métodos de manejo das plantas daninhas nas lavouras de arroz irrigado, com intuito de minimizar o uso de herbicidas, requer entendimento das relações de interferência entre as plantas daninhas e a cultura. Objetivou-se com trabalho avaliar a influência de épocas de início da irrigação por inundação da lavoura de arroz irrigado e a interferência do capim-arroz na cultura e comparar as variáveis explicativas população de plantas, massa seca aérea, cobertura do solo e área foliar pelas plantas de capim-arroz, visando identificar a que propicia melhor ajuste dos dados ao modelo. Para isso, foi instalado um experimento no ano agrícola 2005/06, em delineamento experimental completamente casualizado, sem repetição. Os tratamentos utilizados foram épocas de início da irrigação: 1, 10 e 20 dias após a aplicação dos tratamentos herbicidas (DAT) e populações de plantas de capim-arroz. As populações de capim-arroz foram de $0,6,8,14$, $20,28,42,66$ e 200; 0, 4, 6, 50, 66, 88, 92 e 200; e $0,10,12,32,42,74,166,174$ e 178 plantas $\mathrm{m}^{-2}$, para as épocas de entrada de água aos 1 , 10 e 20 DAT, respectivamente, perfazendo um total de 26 unidades experimentais. A perda de produtividade de grãos da cultura em função das variáveis explicativas população, massa seca aérea, área foliar e cobertura do solo das plantas de capim-arroz foi relacionada pelo uso de modelo de regressão não-linear da hipérbole retangular. O modelo da hipérbole retangular estima adequadamente as perdas de produtividade da cultura do arroz irrigado pela interferência do capim-arroz. A antecipação da entrada de água na lavoura favorece positivamente a habilidade competitiva das plantas de arroz, cultivar BRS-Pelota, com relação às plantas de capim-arroz. A variável população de plantas apresenta melhor ajuste dos dados ao modelo, comparativamente às demais.
\end{abstract}

Palavras-chave: competição, manejo integrado, modelos não-lineares.

\begin{abstract}
The adoption of new weed management methods for flooded rice, aiming to reduce the use of herbicides requires quantitative knowledge about the weed-crop interference relations. The objectives of this research were to evaluate flooding start timing influence on the rice crop and barnyardgrass interference in the crop, as well as to compare the explicative variables plant population, dry weight, soil covering and leaf area to identify the one providing a better data adjustment to the model. Thus, a trial was carried out during the 2005/2006 growing season, arranged in a completely randomized design, with no replication. The treatments were flooding timing at: 1,10 and 20 days after herbicide treatment (DAT), and barnyardgrass populations of 0 , 6, 8, 14, 20, 28, 42, 66 and 200; 0, 4, 6, 50, 66, 88, 92 and 200; 0, 10, 12, 32, 42, 74, 166, 174
\end{abstract}

Recebido para publicação em 7.5.2007 e na forma revisada em 29.11.2007.

Parte da Dissertação de Mestrado do segundo autor apresentada ao Programa de Pós-Graduação em Fitossanidade da UFPelPelotas-RS; ${ }^{2}$ Eng - -Agr ${ }^{\circ}$., Dr., Prof. da Faculdade de Agronomia Eliseu Maciel da Universidade Federal de Pelotas - UFPel (Bolsista do CNPq); ${ }^{3}$ Eng $^{\text {- }}$ Agr ${ }^{\circ}$, aluno do Programa de Pós-Graduação em Fitossanidade da UFPel, Caixa Postal 354, 96010-900, Capão do Leão-RS, <galonleandro@ig.com.br>; ${ }^{4}$ Aluno de graduação da Faculdade de Agronomia Eliseu Maciel - UFPel. 
and 178 plants $\mathrm{m}^{-2}$, for flooding at 1,10 and 20 DAT, respectively, resulting in 26 experimental units. Crop yield loss in function of the explicative variables population, canopy dry mass, leaf area and soil coverage of barnyardgrass plants were related by the rectangular hyperbole nonlinear regression. The rectangular hyperbole appropriately estimates crop yield loss of flooded rice due to barnyardgrass interference. Flooding anticipation modifies the competitive ability of rice plants $c v$. BRS-Pelota in relation to barnyardgrass plants. The variable plant population fits better to the model, when compared to the other variables.

Keywords: competition, integrated managements, nonlinear models.

\section{INTRODUÇÃO}

As plantas daninhas competem com a cultura do arroz por luz, água e nutrientes, constituindo-se em um dos principais fatores limitantes da produtividade nas lavouras de arroz irrigado do Brasil (Sosbai, 2005). A falta de controle das plantas daninhas durante o ciclo de desenvolvimento da cultura do arroz irrigado pode ocasionar perdas na produtividade de grãos na ordem de 80 a 90\% (Andres \& Machado, 2004).

Independentemente do sistema de cultivo, o controle químico é o método mais amplamente utilizado, em decorrência da alta eficiência e praticidade. A inundação do solo com a manutenção de uma lâmina de água permanente sobre a superficie constitui método de controle de plantas daninhas complementar ao quimico, pois, além de ativar muitos herbicidas de solo, atua como barreira física que impede a germinação e o desenvolvimento de muitas espécies de plantas daninhas (Andres \& Machado, 2004).

Tradicionalmente, a irrigação da lavoura de arroz inicia-se aos 30 dias após aplicação dos herbicidas (DAT) pós-emergentes (Sosbai, 2005). O momento ideal de início da irrigação relaciona-se à otimização do uso da água, ao impacto ambiental, ao custo de energia, ao controle de plantas daninhas e à ecofisiologia da cultura (Freitas, 2004). A irrigação logo após a aplicação dos herbicidas tanto pode auxiliar no controle das plantas daninhas, como melhorar a produtividade de grãos da cultura.

Quando o início da irrigação por inundação ocorrer dentro do período recomendado - 15 a 30 dias após a emergência (DAE) - a produtividade de grãos normalmente não é afetada, desde que ocorra precipitação pluvial regular, antes de começar a inundação da lavoura (Andres \& Machado, 2004). A antecipação do início da irrigação, de 35 para 15 DAE (Wielewicki et al., 1998), ou o fornecimento de água por maior período de tempo durante o ciclo da cultura (Del Giudice, 1983), são estratégias que contribuem para o incremento da massa da matéria seca da parte aérea das plantas de arroz, resultando no melhor aproveitamento da radiação solar incidente, podendo incrementar a produtividade de grãos (Carlesso et al., 1998).

A adoção do controle químico, em lavouras de arroz irrigado, certamente se justifica nos casos em que as elevadas infestações de capim-arroz acarretem altas perdas da produtividade de grãos. Entretanto, perdas menores de produtividade decorrentes de baixas populações da infestante, em determinadas situações, são inferiores aos custos do controle. Outro fator a ser considerado é a crescente preocupação quanto aos efeitos negativos do uso de herbicidas, destacando-se a ocorrência crescente de casos de resistência de plantas daninhas e o potencial de contaminação do ambiente (Devlin et al., 1991; Barcellos et al., 1998).

As perdas de produtividade da cultura podem ser expressas quando se tem o conhecimento da população de plantas daninhas que estão competindo com ela num dado momento. Para isso, pode-se recorrer a modelos matemáticos que permitem realizar simulações da competição entre as plantas cultivadas e as daninhas, com a meta de predizer, em fases iniciais, a perda de produtividade e os possiveis lucros esperados em situações particulares (Agostinetto et al., 2004). 
As vantagens da associação do controle químico com outros métodos reside na possibilidade de controlar as plantas daninhas com uma única aplicação de herbicida em pósemergência, sem necessidade de utilização de produto com longo efeito residual, podendo-se utilizar doses menores e reduzir o dano potencial do herbicida sobre o ambiente e a cultura. A antecipação do início da irrigação aumenta a habilidade competitividade da cultura com a planta daninha, a qual pode ser determinada pelo ajuste de variáveis explicativas em modelos matemáticos. Objetivou-se com o trabalho avaliar a influência de épocas de início da irrigação por inundação da lavoura de arroz irrigado e a interferência do capim-arroz com a cultura e comparar as variáveis explicativas: população de plantas, massa da matéria seca aérea, cobertura do solo e área foliar pelas plantas de capim-arroz, visando identificar a que propicia melhor ajuste dos dados ao modelo.

\section{MATERIAL E MÉTODOS}

Conduziu-se experimento a campo, no Centro Agropecuário da Palma (CAP), pertencente à Universidade Federal de Pelotas (UFPel), localizada no município de Capão do Leão-RS, no ano agrícola 2005/06. O solo da área experimental é classificado como Planossolo Hidromórfico Eutrófico solódico, pertencente à Unidade de Mapeamento Pelotas (Embrapa, 1999).

O delineamento experimental adotado foi o completamente casualizado, sem repetição. Nesta pesquisa, as diferentes populações de capim-arroz funcionaram como repetições, proporcionando a variância necessária para as análises estatísticas pelo modelo não-linear proposto por Cousens (1985). Cada unidade experimental (parcela) compreendeu área de $11,05 \mathrm{~m}^{2}(5,0 \times 2,21 \mathrm{~m})$. Os tratamentos englobaram três épocas de entrada de água $(1,10 \mathrm{e}$ 20 dias após aplicação dos tratamentos herbicidas - DAT) e populações de capim-arroz. As populações de capim-arroz foram de $0,6,8,14$, 20, 28, 42, 66 e 200; $0,4,6,50,66,88,92$ e 200; e 0,10,12,32,42,74,166, 174 e 178 plantas $\mathrm{m}^{-2}$, para as épocas de entrada de água aos 1, 10 e 20 DAT, respectivamente, perfazendo um total de 26 unidades experimentais. Em razão de a planta daninha capim-arroz ser proveniente do banco de sementes do solo, o estabelecimento das populações foi variado, pois fatores como infestação, vigor, umidade, entre outros, impedem que se estabeleça exatamente o mesmo número de plantas por área (unidade experimental).

O preparo do solo para instalação do experimento seguiu o sistema convencional, incluindo aração e gradagem. Como adubação de manutenção, utilizaram-se $30 \mathrm{~kg} \mathrm{ha}^{-1}$ de $\mathrm{N}$, $70 \mathrm{~kg} \mathrm{ha}^{-1}$ de $\mathrm{P}_{2} \mathrm{O}_{5}$ e $60 \mathrm{~kg} \mathrm{ha}^{-1}$ de $\mathrm{K}_{2} \mathrm{O}$, distribuídos em linha no momento da semeadura. Como adubação de cobertura foram usados $115 \mathrm{~kg} \mathrm{ha}^{-1}$ de $\mathrm{N}$ (equivalente a $255 \mathrm{~kg} \mathrm{ha}^{-1}$ de uréia), fracionado em duas aplicações (22 e 68 dias após a emergência da cultura - DAE).

O cultivar reagente foi o BRS-Pelota (ciclo médio), semeado em linhas espaçadas de $0,17 \mathrm{~m}$ e densidade de $125 \mathrm{~kg} \mathrm{ha}^{-1}$, o que permitiu o estabelecimento de população média de 400 plantas $\mathrm{m}^{-2}$. A emergência da cultura ocorreu 20 dias após a semeadura, em decorrência do longo período de estiagem que ocorreu no ano agrícola, sendo necessário saturar o solo (banho) após a semeadura, para facilitar o estabelecimento da cultura e das plantas daninhas. A irrigação permanente da área experimental por inundação foi realizada de acordo com os tratamentos, permanecendo até a colheita do arroz. As demais práticas de manejo utilizadas foram aquelas recomendadas pela pesquisa para a cultura do arroz irrigado (Sosbai, 2005).

As populações de capim-arroz competidores foram compostas por duas espécies, Echinochloa colona e E. crusgalli, que foram estabelecidas a partir do banco de sementes do solo, pela aplicação do herbicida cyhalofop-butyl (270 $\left.\mathrm{g} \mathrm{ha}^{-1}\right)+$ adjuvante Iharol (1,5 L ha-1), quando a cultura se encontrava nos estádios fenológicos $V_{2}$ (duas folhas) a $V_{3}$ (três folhas) (9 DAE) e as plantas daninhas, nos estádios de duas folhas a um afilho. A aplicação do herbicida foi feita com pulverizador costal, pressurizado a $\mathrm{CO}_{2}$, recebendo pressão constante de $254 \mathrm{KPa}$, equipado com barra de $2 \mathrm{~m}$, contendo quatro pontas de pulverização (XR TeeJet ${ }^{\circledR}$ ) das séries 110.02, possibilitando aplicação de $150 \mathrm{~L} \mathrm{ha}^{-1}$ de calda herbicida. Foi realizada a contagem do número de plantas de capim-arroz por $\mathrm{m}^{2}$, em cada unidade experimental; em razão disso, protegeu- 
se as que eram fator de teste com copos ou chapas plásticas, para que não sofressem danos do herbicida. As demais plantas daninhas existentes na área experimental foram controladas através de monda.

O herbicida cyhalofop-butyl, \{butil (R) -2[4(4-cyano-2-fluorophen oxy) phenoxy] propionate)\}, foi escolhido devido ao controle de capim-arroz, à seletividade à cultura e por não persistir no solo e/ou na água (Vencill, 2002).

As avaliações das populações das plantas (PP) de capim-arroz, massa seca aérea (MSA), área foliar (AF) e cobertura do solo (CS) foram realizadas aos $21 \mathrm{DAE}$ da cultura. A época foi escolhida em razão de ser a mais usual para aplicação de herbicida pós-emergente.

Para determinação da variável explicativa $\mathrm{PP}$, foram realizadas contagens das plantas presentes em duas áreas de $0,25 \mathrm{~m}^{2}(0,5 \times 0,5 \mathrm{~m})$ por parcela. A MSA das plantas de capim-arroz $\left(\mathrm{g} \mathrm{m}^{-2}\right)$ foi determinada pelas coletas das plantas contidas em área de $0,25 \mathrm{~m}^{2}$ por parcela e secagem em estufa a $65^{\circ} \mathrm{C}$, até massa constante. A quantificação da AF da planta daninha foi realizada com integrador eletrônico de área foliar, utilizando as folhas das plantas colhidas para avaliação da MSA. A CS pelas plantas de capim-arroz foi avaliada visualmente, de modo individual, por dois avaliadores, utilizando-se escala percentual, na qual a nota zero corresponde à ausência de cobertura do solo e a nota 100 representa cobertura total do solo.

A quantificação da produtividade de grãos do arroz foi obtida pela colheita das panículas em área útil de $4,5 \mathrm{~m}^{2}$ (3 x 1,5 m), de cada unidade experimental, quando o teor de umidade dos grãos atingiu aproximadamente $22 \%$. Após pesagem dos grãos, determinou-se a sua umidade, sendo as massas corrigidas para teor de $13 \%$ de umidade. Com os dados da produtividade de grãos, foram calculadas as perdas percentuais em relação às parcelas mantidas sem infestação (testemunhas), de acordo com a equação 1 :

$$
\text { Perda }(\%)=\left(\frac{R a-R b}{R a}\right) \times 100 \quad \text { Equação } 1
$$

em que $R a$ e $R b$ : produtividade da cultura sem ou com presença de capim-arroz, respectivamente.

Anteriormente à análise dos dados, os valores de MSA $\left(\mathrm{g} \mathrm{m}^{-2}\right)$, CS (\%) e AF $\left(\mathrm{cm}^{2} \mathrm{~m}^{-2}\right)$ foram multiplicados por 100, dispensando-se assim o uso do fator de correção no modelo (Rizzardi et al., 2003; Agostinetto et al., 2004). As relações entre perdas percentuais de produtividade do arroz cultivado, em função das variáveis explicativas, foram calculadas separadamente para cada época de entrada de água na lavoura, utilizando-se o modelo de regressão não-linear derivada da hipérbole retangular, de acordo o proposto por Cousens em 1985 (equação 2):

$$
P p=\frac{(i * X)}{\left(1+\left(\frac{i}{a}\right) * X\right)}
$$

Equação 2

em que $\mathrm{Pp}=$ perda de produtividade $(\%) ; X=$ PP, MSA, CS ou AF do capim-arroz; e $i$ e $a=$ perdas de produtividade (\%) por unidade de plantas de capim-arroz quando o valor da variável se aproxima de zero e quando tende ao infinito, respectivamente.

$\mathrm{O}$ ajuste dos dados ao modelo foi realizado utilizando o procedimento Proc Nlin do programa computacional SAS (SAS, 1989). Nos cálculos, utilizou-se o método de Gauss-Newton, o qual, por sucessivas iterações, estima os valores dos parâmetros, nos quais a soma dos quadrados dos desvios das observações, em relação aos ajustados, é mínima (Ratkowsky, 1983).

O valor da estatística $\mathrm{F}$, a $5 \%$ de probabilidade, foi utilizado como critério de análise dos dados ao modelo. O critério de aceitação do melhor ajuste dos dados ao modelo baseou-se no maior valor do coeficiente de determinação $\left(R^{2}\right)$ e no menor valor do quadrado médio do resíduo (QMR). O valor de $\mathrm{F}$ foi obtido através da hipérbole retangular de Cousens (1985), sendo, portanto, calculado pela própria regressão nãolinear.

\section{RESULTADOS E DISCUSSÃO}

Os valores da estatística $\mathrm{F}$ foram significativos para todas as variáveis explicativas e niveis dos fatores estudados (Figuras 1 a 4). De modo geral, os dados ajustaram-se 


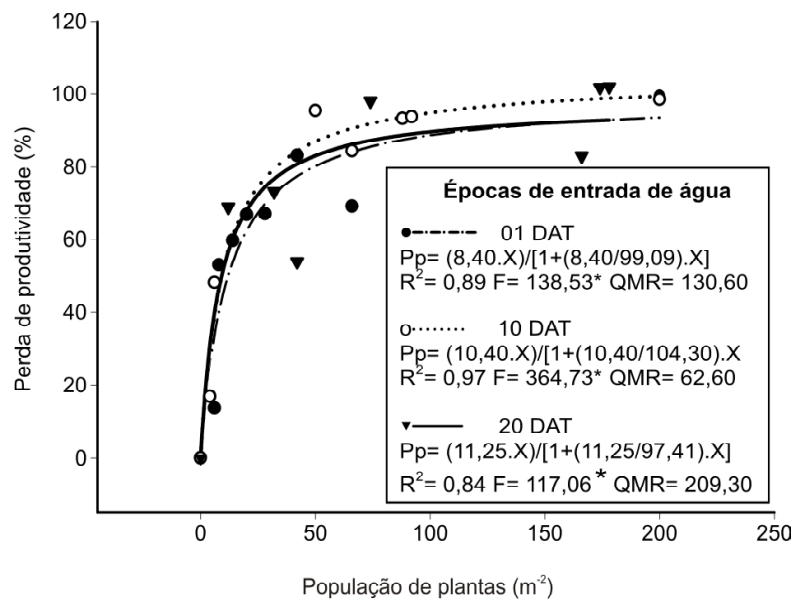

Figura 1 - Perda de produtividade $(\mathrm{Pp})$ de grãos de arroz, cultivar BRS-Pelota, em função da população de capimarroz e das épocas de entrada de água, aos 21 DAE. CAP/ UFPel, Capão do Leão-RS, 2005/06. (DAT: dias após a aplicação dos tratamentos herbicidas; $\mathrm{R}^{2}$ : coeficiente de determinação; QMR: quadrado médio do resíduo; * Significativo a $5 \%$ ).

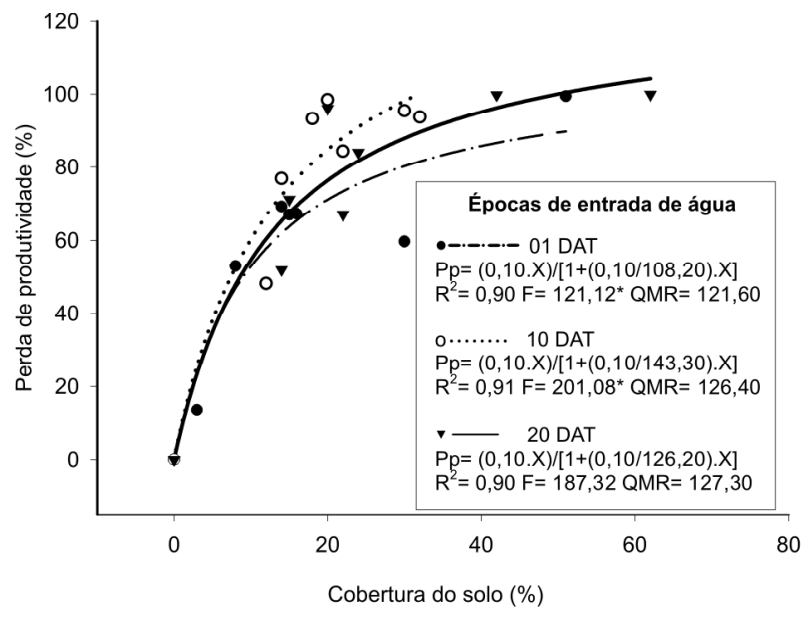

Figura 3 - Perda de produtividade $(\mathrm{Pp})$ de grãos de arroz, cultivar BRS-Pelota, em função da cobertura do solo pela folhagem de capim-arroz e das épocas de entrada, aos 21 DAE. CAP/UFPel, Capão do Leão-RS, 2005/06. (DAT: dias após a aplicação dos tratamentos herbicidas; $\mathrm{R}^{2}$ : coeficiente de determinação; QMR: quadrado médio do resíduo; * Significativo a $5 \%$ ).

satisfatoriamente ao modelo da hipérbole retangular, com elevados valores de $\mathrm{R}^{2}$ e baixo $\mathrm{QMR}$, o que caracteriza bom ajuste ao modelo.

Em todas as variáveis explicativas, observou-se, em geral, melhor ajuste dos dados ao modelo para as duas primeiras épocas de entrada de água na lavoura (1 ou 10 DAT),

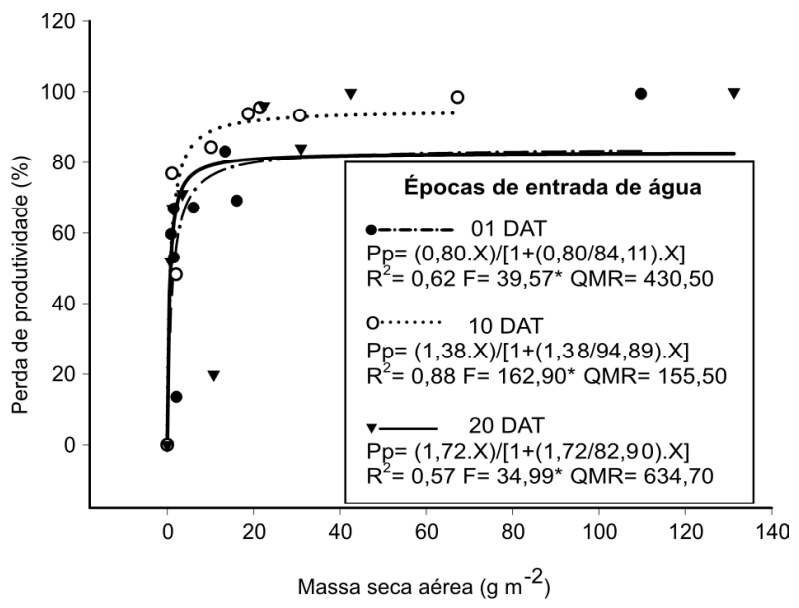

Figura 2 - Perda de produtividade (Pp) de grãos de arroz, cultivar BRS-Pelota, em função da massa seca aérea de capim-arroz e das épocas de entrada de água, aos 21 DAE. CAP/UFPel, Capão do Leão-RS, 2005/06. (DAT: dias após a aplicação dos tratamentos herbicidas; $\mathrm{R}^{2}$ : coeficiente de determinação; QMR: quadrado médio do resíduo; * Significativo a $5 \%$ ).

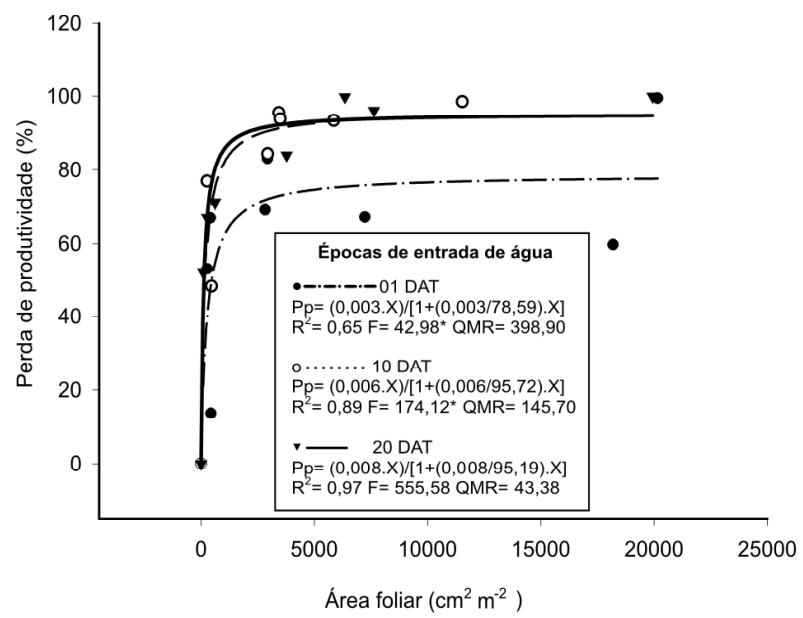

Figura 4 - Perda de produtividade (Pp) de grãos de arroz, cultivar BRS-Pelota, em função da área foliar de capimarroz e das épocas de entrada de água, aos 21 DAE. CAP/ UFPel, Capão do Leão-RS, 2005/06. (DAT: dias após a aplicação dos tratamentos herbicidas; $\mathrm{R}^{2}$ : coeficiente de determinação; QMR: quadrado médio do resíduo; * Significativo a $5 \%$ ).

confirmando, assim, a hipótese de que a antecipação do início da irrigação aumenta a habilidade competitiva da cultura em relação ao capim-arroz (Figuras 1 a 4).

Ao analisar o parâmetro $i$, considerado um indice para comparar a competitividade relativa entre espécies (Swinton et al., 1994), 
verificou-se, para todas as variáveis, que o atraso na entrada de água na lavoura aumentou a habilidade competitiva do capim-arroz em relação ao cultivar de arroz BRS-Pelota (Figuras 1 a 4). Resultados similares foram obtidos por Carlesso et al. (1998), os quais relataram que a antecipação do início da irrigação na lavoura de arroz irrigado proporcionou maior desenvolvimento das plantas, favorecendo o estabelecimento da cultura, em detrimento das plantas daninhas.

Analisando a variável explicativa $\mathrm{PP}$, observou-se que, ao se atrasar a entrada de água em 10 ou 20 DAT, ocorreram perdas médias na produtividade de grãos de 24 ou $34 \%$, respectivamente, comparando com 1 DAT(Figura 1). De maneira similar, Menezes \& Ramírez (2003) observaram queda na produtividade de grãos de arroz de $12 \%$ ao se atrasar em 20 DAE a entrada de água na lavoura.

A variável explicativa MSA apresentou incremento no parâmetro $i$ em 73 ou $115 \%$ ao se retardar em 10 ou 20 dias a entrada de água, respectivamente, comparando com a entrada de água a 1 DAT (Figura 2). O atraso na entrada de água na lavoura em 20 ou 30 DAE provocou queda da produtividade de MSA da ordem de 30 ou $29 \%$, respectivamente, comparando-se com a irrigação efetuada aos 10 DAE (Menezes \& Ramírez, 2003).

Os resultados obtidos para a CS demonstraram que o atraso na irrigação da lavoura não ocasionou diferenças quanto ao parâmetro $i$ entre as diferentes épocas de entrada de água (Figura 3). Observou-se para a variável AF que, à medida que houve atraso de 1 para 10 DAT na irrigação, o capim-arroz duplicou a capacidade competitiva em relação à cultura (Figura 4). Pesquisas demonstram que plantas de arroz submetidas à deficiência de água no solo, nas fases iniciais do ciclo de desenvolvimento, apresentam menor porte, reduzida área foliar e baixo índice de afilhamento, além de menor competitividade com plantas daninhas (Marchezan, 1994; Carlesso et al., 1998). De acordo com Carlesso et al. (1998), a antecipação em $15 \mathrm{DAE}$ na entrada de água na lavoura aumentou o índice de área foliar e o crescimento vegetativo e favoreceu o estabelecimento do arroz.

Planta Daninha, Viçosa-MG, v. 25, n. 4, p. 689-696, 2007
Em todas as variáveis explicativas testadas, o modelo da hipérbole retangular não superestimou o parâmetro $a$, com exceção da PP para a segunda época de entrada de água e a CS em todas as épocas de entrada de água, as quais apresentaram perdas máximas de produtividade superiores a $100 \%$ (Figuras 1 a 4). Resultados de perdas superiores a $100 \%$ são biologicamente irreais e ocorrem quando a amplitude de população de plantas daninhas é excessivamente estreita ou quando os maiores valores da população não são suficientes para produzir resposta assintótica de perda de produtividade (Cousens, 1985; Yenish et al., 1997; Askew \& Wilcut, 2001; Agostinetto et al., 2004). Optou-se por não limitar as perdas de produtividade em $100 \%$, para não influenciar a estimativa do parâmetro $i$, o que poderia resultar em menor previsibilidade (Streibig et al., 1989). Resultados semelhantes aos encontrados neste trabalho foram observados por Swinton et al. (1994), Askew \& Wilcut (2002) e Agostinetto et al. (2004).

Os valores do parâmetro $a$ para a variável $\mathrm{PP}$ variaram em função das épocas de entrada de água, sendo superiores a $100 \%$ somente quando a água entrou na lavoura aos 10 DAT (Figura 1). Já para a variável explicativa MSA, os valores não foram superestimados pelo modelo (Figura 2). Os resultados obtidos com as variáveis PP e MSA concordam com os de Castillo et al. (1992), que relataram diminuição na produção de MSA e na produtividade de grãos da cultura do arroz ao alternarem a irrigação de 15 para 35 dias após a implantação da cultura. $\mathrm{O}$ atraso de 20 dias na entrada de água reduziu mais de 50\% a MSA das plantas de arroz, quando comparado com o atraso de cinco dias (Freitas, 2004). Segundo esse autor, ao se irrigar a lavoura logo após a aplicação dos herbicidas, verificou-se comportamento similar para produção de MSA das plantas de capim-arroz.

As perdas máximas de produtividade $(a)$ para a variável CS foram superestimadas em todas as épocas de entrada de água na lavoura (Figura 3). Esses resultados podem decorrer do fato de as populações das plantas de capimarroz terem sido insuficientes para estimar adequadamente a perda máxima de produtividade, conforme discutido anteriormente. 
A variável explicativa $\mathrm{AF}$ apresentou perdas máximas de produtividades de arroz inferiores a $100 \%$ em todas as épocas de entrada de água na lavoura (Figura 4). No entanto, observou-se que, ao atrasar a época de entrada de água em 10 e 20 DAT, elevou-se o valor do parâmetro $a$ em 22 e $21 \%$, respectivamente, com relação à primeira época de entrada de água. Nesse sentido, Freitas (2004) constatou redução na produtividade de grãos de arroz à medida que atrasou a entrada de água na lavoura.

A comparação entre variáveis explicativas para os fatores estudados, considerando-se os maiores valores médios do $\mathrm{R}^{2} \mathrm{e}$ os menores valores médios do QMR, demonstrou que $\mathrm{PP}>\mathrm{CS}>\mathrm{AF}>\mathrm{MSA}$, em relação ao ajuste ao modelo (Figuras 1, 2, 3 e 4).

Considerando a produtividade média do arroz irrigado no Rio Grande do Sul nas últimas 10 safras, de $5.580 \mathrm{~kg} \mathrm{ha}^{-1}$, o preço médio de 9,0 dólares por saca de $50 \mathrm{~kg}$ e o custo de controle de plantas daninhas em torno de 87,00 dólares ha-1 (Irga, 2006), estima-se que o custo de controle equivale a $9 \%$ da produção. Assim, ao utilizar a variável explicativa PP de capim-arroz e tendo-se como base o parâmetro $i$, avaliado aos $21 \mathrm{DAE}$ (Figura 1), estima-se que a presença de uma única planta de capim-arroz $\mathrm{m}^{-2}$, para as épocas de entrada de água de 1 , 10 ou 20 DAT, ocasionará perdas de produtividade de 8,$4 ; 10,4$ e $11,3 \%$, respectivamente.

Os resultados demonstram que as perdas de produtividade por interferência de uma planta $\mathrm{m}^{-2}$ do capim-arroz não justificam a adoção de medidas de controle somente quando a entrada de água ocorrer em 1 DAT. Isso demonstra que o capim-arroz é muito competitivo e mesmo baixas populações ou medidas de controles que não eliminem toda a infestação podem não ser suficientes para evitar perdas de produtividade que superem o custo do controle.

O modelo de regressão não-linear da hipérbole retangular estima adequadamente as perdas de produtividade de grãos de arroz irrigado ocasionadas pela interferência de capim-arroz à cultura em função de épocas de entrada de água na lavoura. A antecipação da época de entrada de água na lavoura incrementa a habilidade competitiva das plantas de arroz, cultivar BRS-Pelota, com relação às plantas de capim-arroz. A utilização da variável população de plantas de capim-arroz em modelo de previsão de perda de produtividade de grãos de arroz permite ajuste mais satisfatório dos dados do que outras variáveis. A variável cobertura do solo pela folhagem de capim-arroz demonstra ter maior potencial para substituir a população de plantas no modelo da hipérbole retangular para previsão da perda de produtividade de grãos de arroz do que a massa seca aérea e área foliar.

\section{AGRADECIMENTOS}

À Coordenação de Aperfeiçoamento de Pessoal de Nivel Superior (CAPES), à Fundação de Amparo à Pesquisa do Estado do Rio Grande do Sul (FAPERGS) e ao Conselho Nacional de Desenvolvimento Científico e Tecnológico (CNPq), pelas concessões de bolsas.

\section{LITERATURA CITADA}

AGOSTINETTO, D. et al. Perdas de rendimento de grãos na cultura de arroz irrigado em função da população de plantas e da época relativa de emergência de arroz-vermelho ou de seu genótipo simulador de infestação de arroz-vermelho. Planta Daninha, v. 22, n. 2, p. 175-183, 2004.

ANDRES, A.; MACHADO, S. L. O. Plantas daninhas em arroz irrigado. In: GOMES, A. S.; MAGALHÃES JR., A. M. (Eds.). Arroz irrigado no Sul do Brasil. Brasília: Embrapa Informação Tecnológica, 2004. p. 457-546.

ASKEW, S. D.; WILCUT, J. W. Tropic croton interference in cotton. Weed Sci., v. 49, p. 184-189, 2001.

ASKEW, S. D.; WILCUT, J. W. Pale smartweed interference and achene production in cotton. Weed Sci., v. 50, p. 357363, 2002.

BARCELLOS, L. C.; CARVALHO, Y. C.; SILVA, A. L. Estudo sobre a penetração de gotas de pulverização no dossel da cultura da soja [Glycine max (L.) Merrill].

Eng. Agríc., v. 6, p. 81-94, 1998.

CARLESSO, R. et al. Índice de área foliar e altura de plantas de arroz submetidas a diferentes práticas de manejo. R. Bras Eng. Agríc. Amb., v. 2, p. 268-272, 1998.

CASTILlO, E. G.; BURESH, R.; INGRAM, J. K. Lowland rice yield affected by timing of water deficit and nitrogen fertilization. Agron. J., v. 84, p. 152-159, 1992. 
COUSENS, R. An empirical model relating crop yield to weed and crop density and a statistical comparison with other models. J. Agric. Sci., v. 105, p. 513-521, 1985.

DEL GIUDICE, R. M. Absorção cumulativa de nutrientes minerais em duas variedades de arroz (Oryza sativa L.) cultivadas em três diferentes níveis de disponibilidade de água. Campinas: Fundação Cargill, 1983. $110 \mathrm{p}$.

DEVLIN, D. L.; LONG, J. H.; MADDUX, L. D. Using reduced rates of post emergence herbicides in soybeans (Glycine max). Weed Technol., v. 5, p. 834-840, 1991.

\section{EMPRESA BRASILEIRA DE PESQUISA} AGROPECUÁRIA - EMBRAPA. Centro Nacional de Pesquisa Agropecuária de Solos. Sistema brasileiro de classificação de solos. Rio de Janeiro: 1999. 412 p.

FREITAS, G. D. Desempenho do arroz (Oryza sativa L.) cultivar BRS-Pelota e controle de capim-arroz (Echinochloa spp.) submetidos a quatro épocas de entrada d'água após a aplicação de doses reduzidas de herbicidas. 2004. 54 f. Dissertação (Mestrado - Produção Vegetal)-Universidade Federal de Pelotas, Pelotas, 2004.

INSTITUTO RIO-GRANDENSE DO ARROZ - IRGA. Arroz irrigado no RS - área, produção e rendimento. Disponível em: <http://www.irga.rs.gov.br >; Acesso em: 05 out. 2006.

MARCHEZAN, E. Arroz-vermelho, caracterização, prejuízos e controle. Ci. Rural, v. 24, p. 415-421, 1994.

MENEZES, V. G.; RAMÍREZ, H. Rendimento de grãos de arroz irrigado em função do início da irrigação e do controle precoce de plantas daninhas em Cachoeirinha. In: CONGRESSO BRASILEIRO DE ARROZ IRRIGADO, 3.; REUNIÃO DA CULTURA DO ARROZ IRRIGADO, 25. 2003, Balneário Camboriú. Anais... Itajaí: EPAGRI, 2003. p. 190-192.
RATKOWSKY, D. A. Nonlinear regression modeling: a unified practical approach. New York: Marcel Dekker, 1983. p. 135-154.

RIZZARDI, M. A. et al. Ajuste de modelo para quantificar o efeito de plantas daninhas e épocas de semeadura no rendimento de soja. Pesq. Agropec. Bras., v. 38, p. 35-42, 2003.

SOCIEDADE SUL-BRASILEIRA DE ARROZ IRRIGADO - SOSBAI. Arroz irrigado: Recomendações técnicas da pesquisa para o Sul do Brasil. Santa Maria: Universidade Federal de Santa Maria, 2005. 159 p.

STATISTICAL ANALYSIS SYSTEM - SAS. User's guide. 4.ed. Cary: 1989. 846 p.

STREIBIG, J. C. et al. Estimation of thresholds for weed control in Australian cereals. Weed Res., v. 29, p. 117-126, 1989.

SWINTON, S. M. et al. Estimation of crop yield loss due to interference by multiple weed species. Weed Sci., v. 42, p. 103-109, 1994.

VENCILL, W. K. (Ed.). Herbicide handbook. 8.ed. Lawrence: Weed Science Society of America, 2002. 493 p.

WIELEWICKI, A.; MARCHEZAN, E.; STORCK, L. Absorção de nutrientes pelo arroz em resposta à calagem e à época de início da irrigação. Ci. Rural, v. 28, p.17-21, 1998.

YENISH, J. P. et al. Wheat (Triticum aestivum) yield reduction from common milkweed (Asclepias syriaca) competition. Weed Sci., v. 45, p. 127-131, 1997. 